\title{
Agroecologia e Produção Ativa da Escala: princípios para a soberania alimentar - 0 caso da Gleba XV de Novembro
}

\author{
Agroecology and Active Production of the Scale: principles for food sovereignty - the \\ case of Gleba XV de Novembro
}

\begin{abstract}
Agroecología y Producción Activa de la Escala: principios para la soberanía alimentaria - el caso de la Gleba XV de Novembro
\end{abstract}

Valmir José de Oliveira Valério ${ }^{1}$

https://orcid.org/0000-0002-3540-7754

\begin{abstract}
RESUMO: Na agricultura convencional, o sistema alimentar tem o seu funcionamento atrelado à intensa utilização de insumos e equipamentos industrializados. Para a comercialização, este sistema prioriza a quantidade em detrimento da diversidade, o que projeta a crônica dependência em relação aos atravessadores. Nesse contexto, os conceitos de agroecologia e produção ativa da escala trazem em si a perspectiva de emancipação. Assim, este artigo tem por objetivo analisar a relação entre os conceitos de agroecologia e a produção ativa da escala na construção de um sistema alimentar alternativo, voltado ao fortalecimento do direito de todos os países/comunidades ao controle da própria alimentação, de acordo com o conceito de soberania alimentar. Para isso, realizamos inicialmente uma revisão bibliográfica acerca dos principais conceitos utilizados. Em seguida, para compreender a relação entre produção e distribuição na perspectiva aqui adotada, apresentamos também um estudo de caso. Não obstante as adversidades existentes, a prática agroecológica atrelada à iniciativas de construção ativa da escala de comercialização abre as portas para a construção de outro sistema alimentar. Portanto, mais importantes que os resultados imediatos, tais experiências mantém vivas e atualizadas as esperanças por uma alimentação digna, acessível e emancipada.
\end{abstract}

PALAVRAS-CHAVE: Produção de alimentos. Transição agroecológica. Controle da comida.

ABSTRACT: In conventional agriculture, the functioning of the food system is linked to the intense use of industrialized inputs and equipment. For commercialization, this system prioritizes quantity over diversity, which projects chronic dependence on middlemen. In this context, the concepts of agroecology and active scale production bring with them the perspective of emancipation. Thus, this article aims to analyze the relationship between the concepts of agroecology and active scale production in the construction of an alternative food system, aimed at strengthening the right of all countries/communities to control their own food, in accordance with the concept of the food

\footnotetext{
1 Doutor em Geografia pela Faculdade de Ciências e Tecnologia (FCT), Universidade Estadual Paulista (UNESP), campus de Presidente Prudente/SP. Pesquisador do Núcleo de Estudos, Pesquisas e Projetos de Reforma Agrária (NERA). E-mail: valjvalerio@yahoo.com.br.
} 
sovereignty. For this, we initially carried out a literature review about the main concepts used. Then, to understand the relationship between production and distribution in the perspective adopted here, we also present a case study. Despite the existing adversities, the agroecological practice linked to initiatives of active construction of the scale of commercialization opens the doors for the construction of another food system. Therefore, more important than the immediate results, such experiences keep the hopes for a dignified, accessible and emancipated diet alive and updated.

KEYWORDS: Food production. Agroecological transition. Food control.

RESUMEN: En la agricultura convencional, el sistema alimentario tiene su funcionamiento vinculado al uso intenso de insumos y equipos industrializados. Para la comercializacion, este sistema prioriza la cantidad sobre la diversidad, lo que proyecta una dependencia crónica de los intermediarios. En este contexto, los conceptos de agroecología y producción activa de la escala traen consigo la perspectiva de la emancipación. Así, este artículo tiene como objetivo analizar la relación entre los conceptos de agroecología y producción activa de la escala en la construcción de un sistema alimentario alternativo, orientado a fortalecer el derecho de todos los países / comunidades al control de sus propios alimentos, de acuerdo con el concepto de soberanía alimentaria. Para ello, inicialmente realizamos una revisión de la literatura sobre los principales conceptos utilizados. Luego, para comprender la relación entre producción y distribución en la perspectiva adoptada aquí, también presentamos un estudio de caso. A pesar de las adversidades existentes, la práctica agroecológica ligada a iniciativas de construcción activa de la escala de comercialización abre las puertas para la construcción de otro sistema alimentario. Por lo tanto, más importante que los resultados inmediatos, tales experiencias mantienen vivas y actualizadas las esperanzas de una dieta digna, accesible y emancipada.

PALABRAS CLAVES: Producción de alimentos. Transición agroecológica. Control de alimentos.

\section{INTRODUÇÃO}

A realidade do atual sistema hegemônico de produção e distribuição de alimentos está assentada, por um lado, na utilização intensiva de insumos químicos, máquinas e equipamentos industriais e, por outro, no progressivo aumento das distâncias necessárias ao encontro entre produção e consumo de alimentos. Isso penaliza os extremos do sistema alimentar (produtores e consumidores) em benefício dos atravessadores, o que faz com que o movimento da comida tenha por prioridade o lucro dos setores comercial e industrial e não a qualidade e a acessibilidade dos alimentos. Nesse sentido, enquanto direito de produzir e controlar a produção e a distribuição de alimentos nas escalas local e regional, o movimento pela soberania almentar traz em si a possibilidade de construção de um sistema alimentar no qual produção e consumo se encontram de maneira reciprocamente vantajosa.

Para que a soberania alimentar tenha as suas prerrogativas integralmente materializadas, faz-se necessário o cumprimento de, pelo menos, duas dimensões básicas: uma, relacionada à dimensão produtiva e à especificidade dos recursos utilizados, predominantemente internos ou externos ao estabelecimento agrícola. A outra está vinculada às escalas de produção e distribuição, mais especificamente em relação a como o 
agricultor resolve a equação quantidade versus diversidade em relação ao tamanho do seu estabelecimento e, principalmente, aos meios de transporte disponíveis para levar a produção diretamente até os mercados consumidores.

Definida originalmente pela Via Campesina (1996), a soberania alimentar descreve o direito de todas as populações poderem decidir ativamente sobre os próprios hábitos alimentares, de maneira a controlar o que, como, quanto e em em quais condições serão produzidos e distribuídos os alimentos demandados por uma determinada comunidade. Portanto, a materialização da soberania alimentar pressupõe que as dimensões da produção e distribuição estejam sintonizadas às escalas local e regional, de maneira que tanto os recursos produtivos utilizados quanto os mercados acionados para a realização da produção possam ser satisfeitos, na medida do possível, nestas mesmas escalas.

Isto posto, este artigo tem por objetivo analisar a relação entre os conceitos de agroecologia e produção ativa da escala enquanto fundamentos para a materialização da soberania alimentar. Para tanto, inicialmente apresentamos uma revisão bibliográfica acerca dos principais conceitos utilizados, com ênfase na relação de complementaridade entre as dimensões constituintes do processo. Para compreender a articulação entre produção e distribuição na construção ativa da soberania alimentar, analisamos ainda um estudo de caso realizado no Assentamento Gleba XV de Novembro, localizado entre os municípios de Euclides da Cunha Paulista/SP e Rosana/SP, no extremo Oeste do estado de São Paulo (Figura 1).

No que diz respeito aos assentados da Gleba XV e ao acionamento de novas estratégias de produção e comercialização, entre 2018 e 2019 realizamos dois trabalhos de campo no local, nos quais foram entrevistadas um total de 14 pessoas. A escolha dos entrevistados obedeceu ao critério de proximidade com as questões a serem respondidas, sendo dois assentados/lideranças (também produtores) e 12 assentados/produtores. As entrevistas foram do tipo semiestruturada, ou seja, as perguntas foram feitas com base em uma estrutura previamente elaborada e flexível, com a qual buscamos contemplar as questões mais importantes a serem respondidas. Além disso, foram realizadas observações e descrições, tanto nos lotes do Assentamento quanto nas áreas urbanas nas quais os alimentos são comercializados.

Se a compreensão do sistema alimentar pressupõe uma abordagem de conjunto em relação aos seus elementos constituintes, antes disso faz-se necessário um entendimento específico em relação aos principais conceitos que embasam a análise. A esse respeito, apresentamos a seguir alguns dos pressupostos subentendidos à construção da agricultura ecológica, fundada não na utilização generalizada de insumos químicos industrializados, mas na produção interna da maior parte possível dos insumos utilizados, posto que daí resulta o controle sobre a dimensão produtiva da agricultura. 
Figura 1: Localização do Assentamento Gleba XV de Novembro

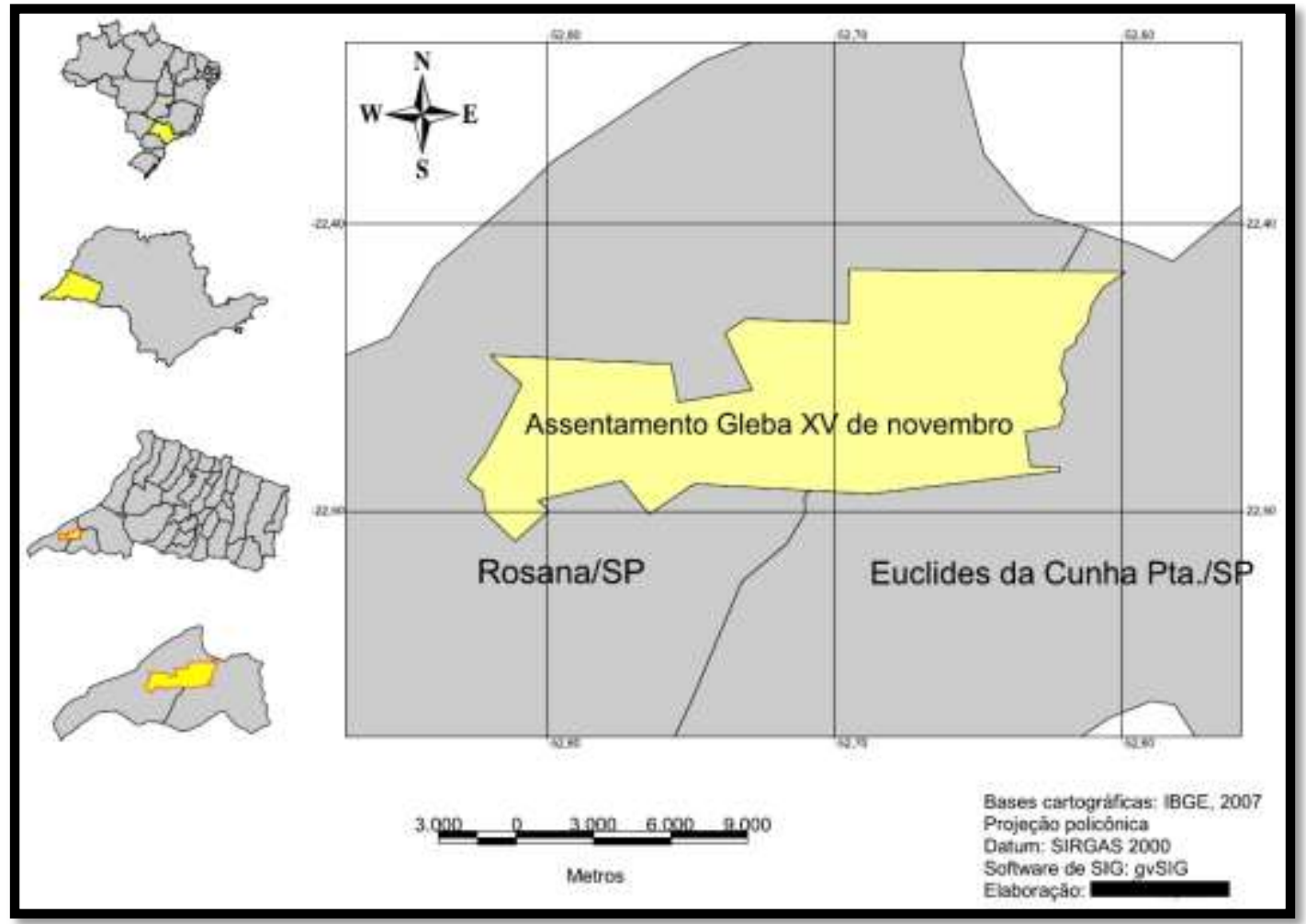

Fonte: IBGE, 2007. Elaboração: autor, 2021.

\section{AGROECOLOGIA: DA DEPENDÊNCIA À SUSTENTABILIDADE}

A constatação dos limites e, sobretudo, das consequências inerentes ao atual sistema hegemônico de produção e distribuição de alimentos, ensejou o surgimento de propostas de transformação da agricultura convencional, cuja produção se dá a partir de uma crônica relação de dependência em relação aos insumos químicos industrializados. Tais propostas buscavam tornar a agricultura viável e compatível, tanto do ponto de vista social, quanto econômico e ambiental, de maneira a recuperar práticas e racionalidades ecológicas. Desse modo, é possível direcionar a ênfase para a progressiva substituição de tecnologias intensivas em insumos industriais, o que possibilita pensar a transformação de todo o sistema produtivo. Com isso, a utilização de insumos químicos de alto custo passa a ser substituída por diferentes tipos de tecnologias de minimização do uso de insumos externos ao estabelecimento produtor (ALTIERI, 2008; CAPORAL, COSTABEBER, 2002; GLIESSMAN et al., 2007).

Entretanto, faz-se necessário reconhecer que a abordagem limitada apenas aos sistemas produtivos não atinge as causas ecológicas amplas, vinculadas aos problemas sociais e ambientais resultantes do desenvolvimento da agricultura "moderna", ou seja, pósindustrial, historicamente ligada ao binômio latifúndio/monocultura e que, atualmente, ganha 
formas renovadas sob o rótulo do agronegócio. Faz-se necessário chamar a atenção para o fato de que a sustentabilidade ecológica dos sistemas produtivos pressupõe elementos que extrapolam qualquer tipo de desafio tecnológico de produção, posto que limitada a apenas esta dimensão a sustentabilidade constitui no máximo uma propaganda. Ou seja, a construção de agroecossistemas efetivamente sustentáveis não pode ser realizada sem uma mudança nos determinantes socioeconômicos que governam "[...] o que é produzido, como é produzido e para quem é produzido" (ALTIERI, 2008, p. 21).

Em termos gerais, a agroecologia nos oferece um amplo arcabouço de técnicas e processos ecológicos para a análise e intervenção em ecossistemas naturais e transformados, substrato no qual podem ser materializados os princípios para uma agricultura socialmente justa e economicamente viável. A abordagem agroecológica tem por prioridade o desenvolvimento de ecossistemas agrícolas capazes de minimizar ao máximo o uso de insumos industrializados, uma vez que complexas interações ecológicas acionam, progressivamente, variados elementos responsáveis pela fertilidade do solo, produtividade dos cultivos e preservação dos ecossistemas agrícolas. Em um agroecossistema a sustentabilidade demanda uma relação equilibrada entre os elementos constituintes, sobretudo quanto à diversidade de plantas e organismos responsáveis tanto pela fertilidade do solo, quanto pelo controle da luz e umidade do sistema produtivo (ALTIERI, 2008; CAPORAL, COSTABEBER, 2002; GLIESSMAN et al., 2007).

Não obstante a expressiva quantidade de projetos de desenvolvimento rural promovidos pelos Estados e organismos internacionais em diversas partes do mundo, problemas como a miséria, a desnutrição, a fome e a degradação ambiental seguem como questões atuais e urgentes. Isso porque os projetos convencionais têm por base a utilização intensa de tecnologias da revolução verde (mecanização, quimificação, etc.), cuja efetividade na promoção do desenvolvimento com o mínimo de equidade e sustentabilidade são geneticamente limitados, posto que a sua lógica aprofunda ainda mais a exclusão social e a deterioração dos recursos. Nesse contexto, a queda da qualidade de vida no campo e o agravamento dos problemas de degradação dos recursos naturais, resultantes do modus operandi da agricultura "moderna", colocam o desenvolvimento sustentável em permanente questionamento. Ainda que controverso e de definição precária, o conceito de sustentabilidade possibilita destacar que a agricultura constitui uma atividade fortemente influenciada pela evolução dos sistemas naturais, sociais e econômicos. Assim, a preservação e a ampliação da biodiversidade dos sistemas agrícolas constituem pressupostos para a sustentabilidade, posto que "[...] quando a biodiversidade é restituída aos agroecossistemas, numerosas e complexas interações passam a estabelecer-se entre o solo, as plantas e os animais" (ALTIERI, 2008, p. 24). 
Todavia, o restabelecimento do equilíbrio ecológico dos sistemas agrícolas é somente um dos objetivos a serem atingidos na construção da agricultura de base ecológica, uma vez que a sustentabilidade não existe sem as histórias e culturas que nutrem e fazem existir a diversidade das agriculturas locais. Nestas, ocorrem diversos ciclos, minerais, energéticos, biológicos e socioculturais, "[...] constituindo o lócus onde se pode buscar uma análise sistêmica e holística do conjunto destas relações e transformações" (CAPORAL, COSTABEBER, 2002, p. 14).

A ciência agroecológica apresenta caminhos metodológicos capazes de transformar 0 envolvimento comunitário em potencial de fortalecimento local e regional. A diversidade é, assim, estratégica na redução dos riscos inerentes à atividade agrícola, uma vez que com isso promove a estabilização da produtividade de longo prazo e a diversidade do regime alimentar, otimizando os resultados com reduzida utilização de recursos (ALTIERI, 2008). Além disso:

\begin{abstract}
A estrutura complexa dos agroecossistemas tradicionais diminui as perdas por ação de pragas, através de uma variedade de mecanismos biológicos. O consorciamento de distintas espécies ajuda a criar habitats para os inimigos naturais das pragas, bem como hospedeiros alternativos para as mesmas. Um cultivo pode ser utilizado como hospedeiro diversivo, protegendo de riscos outros cultivos mais suscetíveis ou mais valorizados economicamente. [...] A mistura de diferentes espécies de plantas ou variedades pode retardar o surto de doenças, reduzir a disseminação de esporos infectados e modificar as condições ambientais, tais como umidade, luminosidade, temperatura e deslocamento do ar, tornando-as menos favoráveis à difusão de certas doenças (ALTIERI, 2008, p. 32-33).
\end{abstract}

Isso ampara o surgimento de novas estratégias de desenvolvimento agrícola, baseadas em propostas concebidas "de baixo para cima", referenciadas nos recursos e demandas locais e regionais. Sob esta perspectiva, a agricultura difere radicalmente daquela referenciada na revolução verde, tanto na dimensão técnica, cuja prioridade passa a estar assentada na utilização de tecnologias de baixo consumo de insumos externos ao estabelecimento, quanto social, com aumento da participação das comunidades locais na elaboração dos projetos de desenvolvimento. Isso porque, ao passo que a revolução verde privilegiou os agricultores minimamente capitalizados e, por conseguinte, dotados dos recursos financeiros para acessarem os "pacotes tecnológicos", na agroecologia a prioridade está na pequena agricultura, principalmente aquelas com maior escassez de recursos. A esse respeito, a utilização de recursos locais reduz os custos de produção, o que aumenta a viabilidade dos sistemas alternativos fundados na construção da agricultura ecológica (ALTIERI, 2008; CAPORAL, COSTABEBER, 2002; GLIESSMAN et al., 2007).

Consequentemente, a garantia de acesso à terra, água, crédito, mercados e tecnologias alternativas é imprescindível para assegurar formas de desenvolvimento 
dotadas de potencial verdadeiramente sustentável. Além disso, a emancipação camponesa em relação aos ditames do capital pressupõe refletir acerca dos significados subentendidos não apenas ao direito de produzir de maneira efetivamente sustentável, mas, principalmente, em relação ao direito de controlar a produção e a distribuição de alimentos, o que enriquece as reflexões no âmbito da soberania alimentar.

A complexificação dos ecossistemas produzidos segundo as técnicas e processos da agroecologia possibilita o equacionamento da relação entre a diversidade de tipos cultivados e as quantidades produzidas por tipo de cultivo em relação ao tamanho do estabelecimento, fortalecendo a pequena produção camponesa ao torná-la compatível (tanto do ponto de vista quantitativo quanto qualitativo) com o abastecimento nas escalas local e regional durante todo o ano.

Em que pesem as possibilidades colocadas pela utilização de técnicas e processos agroecológicos, a força do atual sistema alimentar hegemônico no controle das relações entre produção, distribuição, armazenamento e consumo mantém reféns produtores e consumidores, aprofundando problemas relacionados à fome, desnutrição e degradação ambiental, o que coloca a transformação do sistema agroalimentar no centro dos debates. Para tanto, faz-se necessário pensar a dependência da agricultura para além da dimensão produtiva, de maneira a colocar em evidência os mecanismos de exploração da renda camponesa inerentes à comercialização indireta da produção. Nesse sentido, apresentamos a seguir o conceito de produção ativa da escala, por meio do qual é possível pensar, para além da dimensão produtiva, diferentes estratégias de fortalecimento da pequena agricultura via comercialização direta da produção.

\section{PRODUÇÃo ATIVA DA ESCALA: DO CONTROLE DA PRODUÇÃO AO CONTROLE DA COMERCIALIZAÇÃO}

A escala de encontro entre produção e consumo traz em si os interesses favorecidos e/ou dificultados na configuração do abastecimento alimentar em uma dada porção do espaço. Isso porque, ditados pela lógica de generalização das distâncias, os alimentos são convertidos em um tipo de mercadoria cuja valorização cresce na proporção direta do seu movimento. Logo, quanto mais alargadas as distâncias entre produção e consumo, maiores serão os preços finais e, consequentemente, menor o acesso das famílias aos alimentos, em especial para aquelas de baixo poder aquisitivo.

Igualmente, a distância entre produção e consumo referencia, em grande medida, quanto será pago aos produtores pela sua produção, uma vez que daí serão descontados os custos com transporte e armazenagem. Nesse âmbito, é oportuno o debate sobre a produção ativa da escala, o qual permite pensar a autonomia camponesa atrelada aos 
princípios da agroecologia. De tal modo, agroecologia e produção ativa da escala se encontram na produção de uma outra lógica, substrato para a construção da soberania alimentar.

Emancipada dos limites da abordagem matemática, o conceito de escala possibilita refletir para além da perspectiva cartográfica de medidas e proporções, de modo a identificar diferentes dimensões e contradições intrínsecas aos fenômenos socioespaciais. Assim, analisamos a escala enquanto produto social (a escala geográfica), surgido a partir das relações sociais responsáveis pela sua materialização. Ou seja, a escala como expressão geográfica de processos sociais contraditórios de competição e cooperação, o que torna possível analisar a disputa social pelo estabelecimento de fronteiras entre diferentes espaços (SMITH, 2000).

A produção ativa da escala constitui, além de uma proposta teórico-metodológica para compreender as complexas articulações entre quantidade e diversidade em relação ao tamanho da área disponível para a agricultura em pequenos estabelecimentos camponeses, uma estratégia de identificação dos interesses subentendidos às escalas de comercialização da produção de alimentos. Ademais, enquanto produto socialmente produzido, a escala geográfica contém o potencial de resistência e emancipação, em sintonia com a proposta de Smith (2000).

Através de variadas estratégias de produção e transporte, o campesinato pode resolver a equação quantidade versus diversidade em cada período do ano. Nesse sentido, os recursos de transporte referenciam o controle das escalas de comercialização da produção, o que pode ser desde um veículo de passeio adaptado, um automóvel utilitário ou mesmo uma carroça de tração animal, dentre outras possibilidades. Independentemente do recurso a ser utilizado, o controle da escala de comercialização da produção de alimentos permite superar a dependência em relação aos atravessadores do capital comercial e industrial, o que faz surgirem relações de proximidade referenciadas nos princípios da soberania alimentar.

Entretanto, a equalização entre oferta e demanda pressupõe romper com a lógica do atual sistema hegemônico de produção e distribuição de alimentos, de acordo com o qual a diversidade sucumbe à quantidade. Ao produzirem uma grande quantidade de poucos tipos de cultivos (muita quantidade e pouca diversidade), os produtores ficam, inevitavelmente, reféns dos atravessadores. Com isso, as suas escolhas passam a ser ditadas pelo capital comercial, através dos "intermediários" que, na prática, correspondem a verdadeiros especuladores da alimentação. Dessa maneira, são impostas quantidades mínimas a serem produzidas por tipo de cultivo, pressuposto para que os pequenos agricultores sejam "contemplados" pelo deslocamento do caminhão das empresas atravessadoras. Como 
resultado, o agricultor está sempre "correndo atrás" dos cultivos apontados pelo mercado como os mais adequados para uma determinada conjuntura, o que faz da dependência a marca principal desta relação.

Nesse sentido, o controle da escala de produção e comercialização dos alimentos é estratégico para o fortalecimento da pequena agricultura camponesa, assim como para a construção da sua autonomia frente às relações capitalistas. Analisada a partir das relações sociais responsáveis pela sua produção, a escala aponta, na realidade aqui abordada, para duas principais dimensões. A primeira diz respeito ao equacionamento da relação quantidade versus diversidade em relação às dimensões da área de cultivo disponível. A segunda está diretamente relacionada às possibilidades materiais de transporte da produção até os mercados local e regional, o que possibilita o estabelecimento de relações de proximidade dotadas do potencial de libertar os agricultores das relações de dependência inerentes ao atual sistema hegemônico de produção e distribuição de alimentos.

A diversidade representa, assim, o fundamento para a construção de alternativas voltadas ao encontro entre produção e consumo nas escalas local e regional, não apenas em relação às reduzidas áreas de cultivo (predominantes na agricultura produtora de alimentos), mas, também, no que diz respeito aos meios de transporte disponíveis. No mesmo diapasão, a vulnerabilidade do camponês em relação às adversidades da agricultura, tanto do ponto de vista de mercado, quanto da ocorrência de intempéries climáticas, é influenciada, também, pela diversidade cultivada. Com efeito, quanto maior a diversidade de cultivos, maiores as possibilidades de mercado, sintonizadas às demandas local e regional. Igualmente, com o aumento da diversidade cultivada aumenta, na mesma medida, a segurança do agricultor quanto à ocorrência de eventos climáticos extremos, como frio, seca ou chuvas em excesso.

Todavia, o debate sobre a produção ativa da escala não se restringe ao equacionamento da relação quantidade versus diversidade, uma vez que o alcance dos agricultores aos mercados está lastreado nas suas possibilidades materiais de transporte. A esse respeito, Smith (2000) nos apresenta elementos para pensar a escala enquanto expressão da disputa social e geográfica pelo estabelecimento de fronteiras entre diferentes espaços. Isso porque "[...] é a escala geográfica que define as fronteiras e limita as identidades em torno das quais o controle é exercido e contestado (SMITH, 2000, p. 144). Por conseguinte, "[...] o acesso diferenciado no espaço conduz a diferenças de poder na construção da escala espacial da vida cotidiana" (SMITH, 2000, p. 149).

Para o autor, a segregação dos sujeitos por fronteiras espaciais impostas de maneira vertical torna imperativo pensar estratégias que permitam "saltar as escalas" que restringem a sua mobilidade no espaço. Nesse sentido, a utilização de recursos de transporte é condição sine qua non para a ampliação dos limites responsáveis por restringir a produção e 
reprodução da vida cotidiana a uma parcela específica do espaço. Logo, o conceito de produção ativa da escala destaca a importância do acionamento dos meios de transporte disponíveis, pressuposto para a emancipação dos pequenos produtores de alimentos em relação aos atravessadores do capital comercial e industrial. Isso porque, uma vez lastreada no binômio diversidade/pequenas escalas de produção, os meios de transporte demandados estarão cada vez mais próximos da realidade material dos pequenos produtores.

Em síntese, quantidades produzidas por cultivo, diversidade (número de tipos cultivados), área útil do estabelecimento e escala de circulação da produção se ligam, assim, à especificidade das técnicas utilizadas, o que possibilita identificar os interessses e prioridades contemplados na produção e distribuição de alimentos. A esse respeito, quando comparamos a agricultura "industrial" e a agricultura agroecológica, não podemos deixar de notar que, ao passo que a primeira implica na dependência em relação aos insumos industriais (e aos atravessadores), a segunda pressupõe a emancipação através da produção da maior parte dos insumos utilizados, além de ser adequada à comercialização direta nas escalas local e regional.

Com o objetivo de afastar quaisquer possibilidades de "fetichização" da teoria e, também, para que a mesma esteja embasada na realidade encontrada em campo, apresentamos a seguir o caso do Assentamento Gleba XV de Novembro, com especial atenção para a utilização de técnicas e processos agroecológicos articulados à estratégias de comercialização direta da produção, tais como as "cestas" agroecológicas e as feiras agroecológicas, sintonizadas aos princípios da soberania alimentar.

\section{NAS TRILHAS DA SOBERANIA ALIMENTAR: O CASO DO ASSENTAMENTO GLEBA XV DE NOVEMBRO}

O exemplo da organização de agricultoras e agricultores do Movimento dos Trabalhadores Rurais Sem Terra (MST) assentados na Gleba XV de novembro permite compreender a expressão empírica da produção ativa da escala atrelada aos princípios da agroecologia e da soberania alimentar. Primeiramente, faz-se necessário enfatizar que a construção de uma proposta de transição agroecológica passa, imprescindivelmente, pelo aumento da diversidade cultivada e controle dos materiais e processos produtivos, de maneira que a maioria dos recursos utilizados tenha origem no próprio Assentamento. Esse pressuposto de controle interno da maioria dos recursos utilizados encontra na agroecologia um referencial adequado para a implantação de práticas agroecológicas, portadoras do 
substrato que prepara o caminho para a construção, manutenção e fortalecimento da autonomia na produção camponesa.

A esse respeito, faz-se necessário um esclarecimento. A prática agroecológica é diferente da produção agroecológica propriamente dita, pois enquanto a primeira diz respeito às técnicas e princípios básicos que compõem as referências para a construção da agricultura ecológica, a segunda é o produto já "amadurecido" desta. Nesse sentido, a produção com base em "práticas agroecológicas" traduz o processo de "transição agroecológica". Ou seja, como a agroecologia não pode ser construída "do dia para a noite", impõe-se o cumprimento de "etapas", nas quais a agricultura praticada (pouco diversificada e dependente de insumos externos para a produção e de atravessadores para a comercialização) caminha, cada vez mais, para uma agricultura predominantemente ecológica. Estas "etapas" constituem, para Gliessman et al. (2007), quatro "níveis de transição".

O primeiro nível se relaciona com o aumento da eficiência dos agroecossistemas, principalmente no que se refere à rotação de culturas e associação de cultivos, o que objetiva minimizar a utilização de recursos externos de custos elevados e, além disso, nocivos para o ambiente. O segundo nível pressupõe já a substituição propriamente dita dos insumos convencionais por materiais e processos alternativos, que estejam sintonizados à sustentabilidade do ecossistema produzido. O terceiro nível se inicia com o acúmulo das transformações conquistadas nos níveis anteriores, o que proporciona uma transformação visível do agroecossistema anteriormente cultivado e, por isso, denominado como "redesenho". Em que pesem as vantagens proporcionadas pelos níveis anteriores, sobretudo quanto ao aumento da diversidade e redução do uso de insumos externos, é no quarto nível que acontece o "amadurecimento" do processo, quando são estabelecidas relações diretas entre os que produzem os alimentos, por um lado, e os que consomem os produtos, por outro, tendo como referência o reconhecimento e a valorização do trabalho daqueles que produzem e da saúde dos que consomem, assim como a preservação das culturas e a sustentabilidade, tanto do ambiente quanto dos sistemas alimentares (GLIESSAMAN et al., 2007).

No caso da Gleba XV de Novembro, as práticas agroecológicas têm ainda os passos iniciais, porém já bem encaminhados. Neste ponto, é importante chamar a atenção para o fato de que, para além das concepções técnicas, teóricas e conceituais acerca da ciência agroecológica, é fundamental deixar claro que a construção de uma agricultura alternativa que permita a emancipação da produção camponesa pelo viés ecológico não será ditada pelo rigor acadêmico, mas por exemplos embrionários que ousam dar o primeiro passo nessa direção. 
Como observado no caso em estudo, a introdução do processo de transição agroecológica tem por base uma mistura de troca de saberes e experimentação, por meio da qual são combinadas técnicas e conhecimentos da agricultura convencional, com as novas referências de "como produzir" de maneira mais barata e melhor, que chegam por meio de membros de universidades e assentados com formação em cursos universitários, técnicos ou mesmo experiência prática na área. A adesão às novas práticas se deve, nesse sentido, principalmente a possibilidade de gastar menos e ter melhores resultados, adequados à uma demanda disposta a pagar pelo "valor" de uma alimentação mais justa, saudável e ambientalmente correta (Figura 2).

Figura 2: Produção em transição agroecológica no Assentamento Gleba XV de Novembro

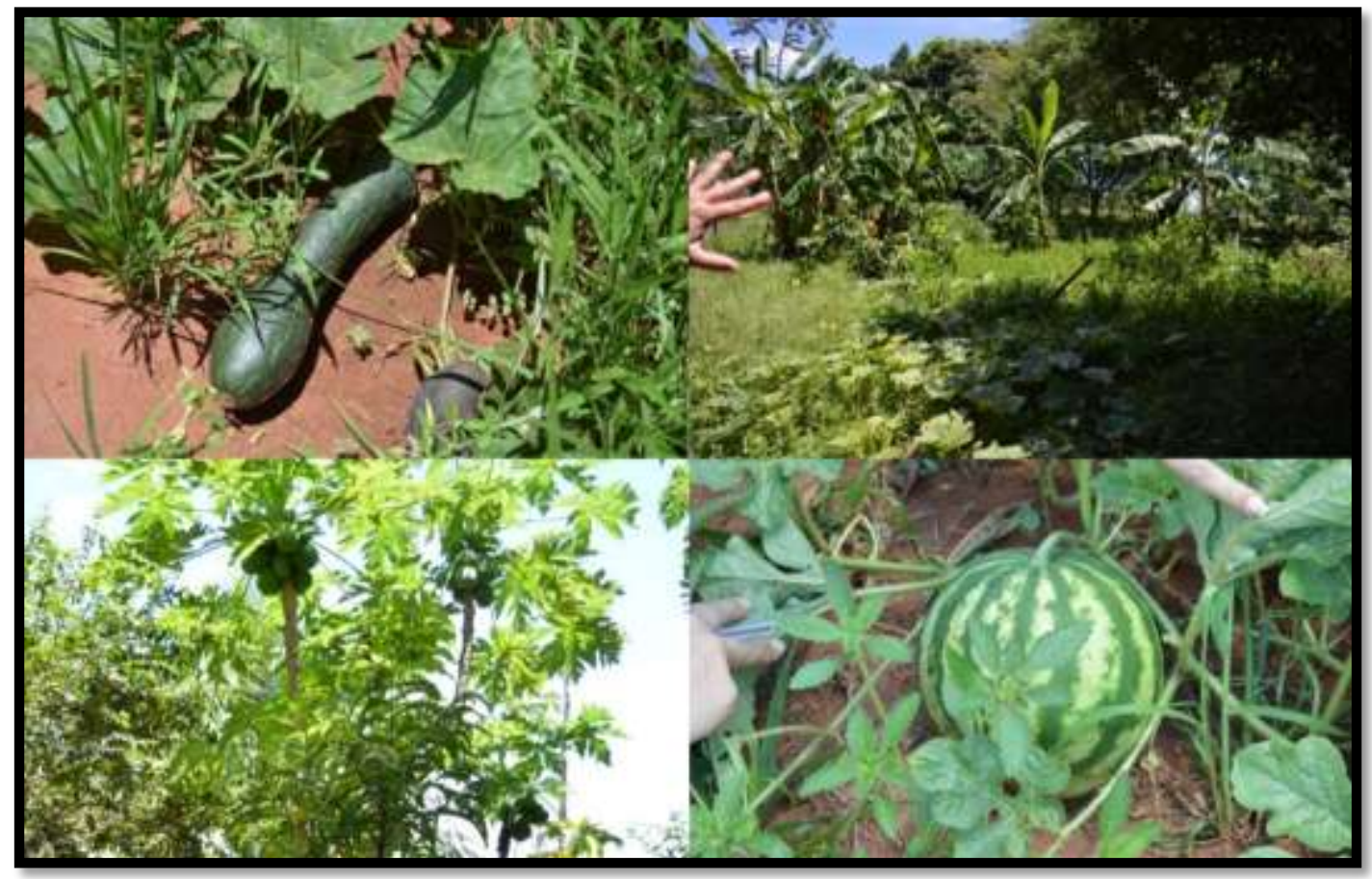

Fonte: trabalho de campo; autor, 2018.

Do total de famílias do Assentamento (criado em 1984 com aproximadamente 500 famílias), em torno de 25 participam dos projetos "cesta" agroecológica e feira agroecológica. De acordo com informações das lideranças entrevistadas, até meados de 2015 aproximadamente metade dos membros do Assentamento tinha parte importante da renda oriunda da participação no Programa de Aquisição de Alimentos (PAA). Porém, desde 2015/2016 houve uma redução drástica das verbas destinadas ao financiamento do programa, ao ponto de chegar, no ano de 2019 , a participação de não mais que $5 \%$ dos assentados.

Com isso, foi inevitável a questão: "e agora"? Para dar resposta a este desafio, algumas famílias se organizaram para buscar caminhos que possibilitem a produção de 
alimentos e a geração da renda resultante, entretanto, agora sob outros referenciais. Consequentemente, o projeto das "cestas" agroecológicas surgiu como resposta à descontinuidade de um programa que "deixou para trás" todo o trabalho investido na produção de campos de cultivo alimentar, de maneira que a partir daí a introdução dos princípios agroecológicos referenciou uma combinação cada vez maior dos saberes da agricultura "tradicional", praticada anteriormente, com as novas formas de "fazer agricultura", ainda em construção.

A área média dos lotes fica em torno de 25 hectares, dos quais a maior parte é dedicada à pecuária leiteira. $O$ cultivo de mandioca constitui a segunda atividade mais importante, com área plantada superior a 1.000 hectares em toda a Gleba. Nesse âmbito, a área destinada ao processo de transição agroecológica ainda é relativamente pequena, sendo difícil estimar a área total abrangida. Porém, tendo em vista o pouco tempo de "amadurecimento" do projeto, a tendência é que mais famílias sejam integradas e, com isso, aumente gradativamente a área de cultivo referenciada nos processos agroecológicos. Igualmente, no que diz respeito à renda gerada, a fase inicial apresenta resultados tímidos, o que não impede que constitua um importante complemento familiar.

Dos muitos obstáculos colocados, a proximidade dos canaviais do agronegócio sucroenergético constitui um dos mais dramáticos e desafiadores. De acordo com assentados entrevistados no local, o maior problema são as pulverizações aéreas realizadas nas vizinhanças dos campos de cultivo, que acarretam prejuízos e perdas de lavouras, relatadas por diversas famílias. Além disso, a proximidade dos canaviais, localizados a poucos metros do assentamento, provoca o aumento da poeira decorrente da movimentação de máquinas e caminhões pesados. Isso traz prejuízos tanto para os cultivos alimentares, pelo acúmulo de poeira nas folhas e flores, quanto para a criação de gado leiteiro, principal fonte de renda no Assentamento, prejudicada pela camada de poeira formada nos pastos que, segundo os entrevistados, faz com que o gado coma menos, resultando no emagrecimento dos animais e na redução da produção de leite.

Em que pesem tais adversidades, em um levantamento realizado no local foram encontrados 44 tipos de cultivos alimentares (Quadro 1). A produção dos lotes é destinada tanto para consumo doméstico quanto para comercialização. Esse fato contribui para a economia de recursos necessários à aquisição externa de alimentos e, dessa maneira, para o aumento da renda disponível para as famílias. No entanto, como os princípios agroecológicos passaram a referenciar as atividades recentemente, o "redesenho" da agricultura (GLIESSAMAN et al., 2007) ainda não foi completado.

Do que foi possível notar a partir das observações e depoimentos em campo, a prioridade está, momentaneamente, no aumento da eficiência do sistema produtivo. Isso é realizado principalmente através da implantação de práticas como rotação de culturas e 
associação de cultivos, o que resulta no aumento imediato da diversidade cultivada por área. Outra estratégia utilizada pelos assentados tem relação com a substituição de insumos externos, caros e perigosos, por recursos alternativos, possíveis de serem produzidos no próprio lote/Assentamento, tais como sementes, mudas, estercos, adubação verde, compostagem e aplicação de "caldas" para o combate às doenças e insetos que acarretem potenciais prejuízos aos cultivos praticados.

Quadro 1: Cultivos alimentares encontrados no Assentamento Gleba XV de Novembro

\begin{tabular}{l} 
Tipos de alimentos \\
\hline Abacate, abacaxi, abóbora, acerola, alface, almeirão, amora, banana, batata doce, berinjela, \\
beterraba, cajá-manga, caju, carambola, cebola, cheiro verde, chuchu, coco, couve, erva cidreira, \\
erva doce, feijão de corda, goiaba, graviola, hortelã, jabuticaba, jaca, jiló, laranja, limão, mamão, \\
mandioca, manga, maracujá, melancia, milho verde, noni, orégano, pepino, pimenta, quiabo, \\
salsinha, tamarindo e tomate cereja.
\end{tabular}

Fonte: trabalho de campo; autor, 2018.

Como a produção por cultivo é limitada, a comercialização por meio das "cestas" agroecológicas "se encaixa" perfeitamente aos volumes demandados pelo projeto, pois na sua composição estão contempladas pequenas quantidades de variados tipos de alimentos, ou seja, a diversidade se sobrepõe à quantidade. Nesse sentido, a produção com base nos princípios agroecológicos assegura constante variedade dos tipos ofertados, posto que a cada época do ano alimentos específicos são produzidos.

Além disso, o equilíbrio entre quantidade e diversidade está intimamente sintonizado às possibilidades materiais de transporte acessíveis aos pequenos agricultores assentados. Isso porque, na maioria dos casos, os mesmos não dispõem de caminhão ou outro tipo de veículo com grande capacidade de carga para transportar quantidades expressivas de mercadorias. Para a realização do transporte dos alimentos, os assentados da Gleba XV utilizam os próprios automóveis particulares (carros e veículos utilitários), com os quais levam a produção dos lotes até os consumidores urbanos.

Para a organização e montagem das "cestas", os alimentos que estarão disponíveis em cada lote são apontados com antecedência pelos assentados participantes do projeto, de maneira a comunicar ao setor responsável pelo planejamento da composição da próxima "cesta", assim como de preparo e reunião dos produtos e da logística de entrega, realizada quinzenalmente em duas unidades universitárias, uma em Presidente Prudente/SP e outra em Rosana/SP. O público consumidor das "cestas" contempla principalmente professores, funcionários e estudantes das próprias unidades universitárias. Entretanto, como observado em campo, o número de consumidores sem vínculo com as instituições tem aumentado gradativamente. 
Por meio da divulgação em redes sociais e troca de informações entre consumidores, a notícia das "cestas" agroecológicas se espalhou em passo acelerado. Beneficiada atualmente pelo apelo do consumo saudável e da sustentabilidade, além de uma certa "tomada de consciência" em relação aos significados políticos subentendidos à maneira específica como nos alimentamos, cada vez mais novos consumidores são incorporados à lista de clientes, o que fortalece o projeto e deixa exemplos valiosos acerca da viabilidade da emancipação camponesa a partir do controle das escalas de produção e comercialização de alimentos (Figura 3).

Figura 3: Entrega das "cestas" agroecológicas dos Assentados da Gleba XV de Novembro no campus da Unesp de Presidente Prudente/SP

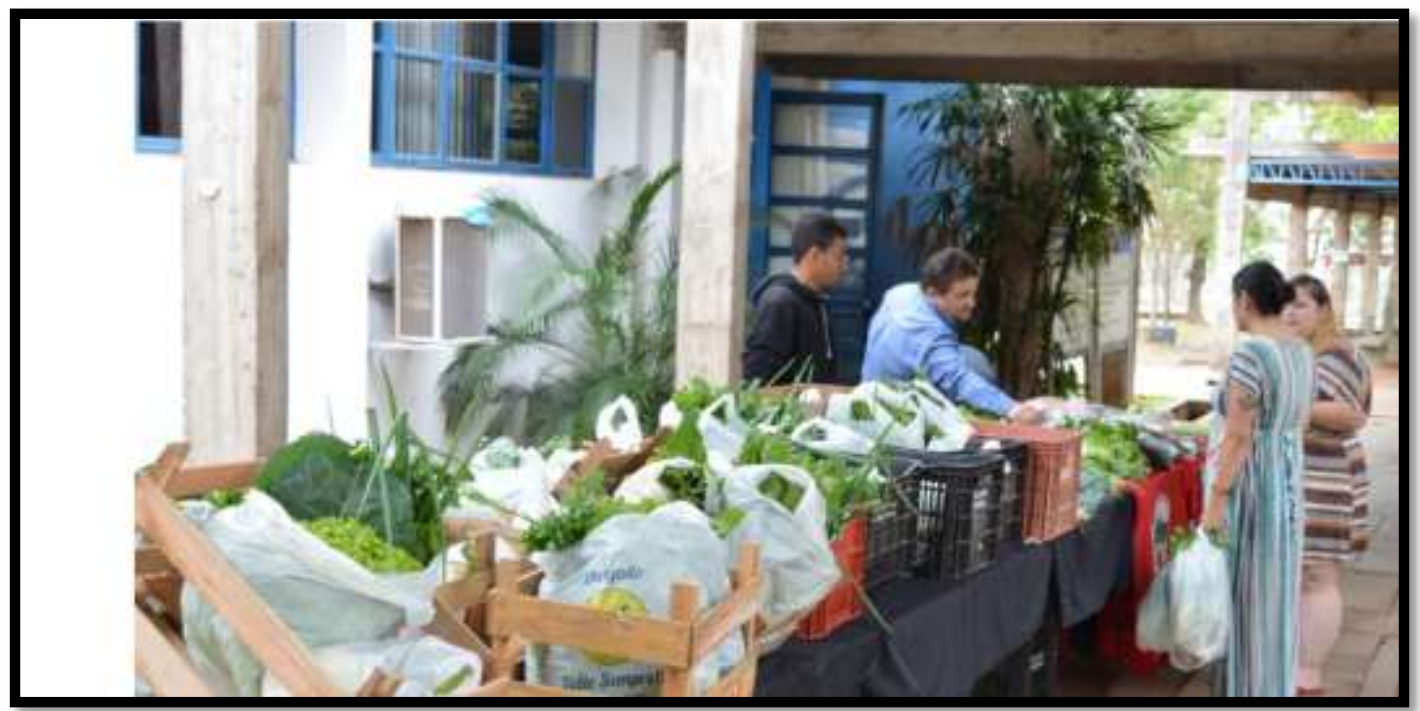

Fonte: trabalho de campo; autor, 2019.

Devido à relativa distância em relação aos mercados consumidores mais expressivos (o município de Presidente Prudente/SP, maior e mais diversificado mercado consumidor da região, fica localizado a uma distância de aproximadamente 160 quilômetros do Assentamento), os recursos de transporte têm importância especial no contexto vivido pelos assentados da Gleba XV de Novembro. Assim, se do ponto de vista dos materiais e processos produtivos a agroecologia oferece uma alternativa acessível e adequada para a prática de uma agricultura diversificada e de pequena escala, no âmbito do controle das escalas de comercialização e sua conversão na renda camponesa é o acesso aos recursos de transporte que assegura o "salto" escalar (SMITH, 2000) que finalmente liberta o produtor das amarras do capital comercial e industrial.

Isso porque, ao venderem diretamente para os consumidores, não apenas afirmam a soberania sobre o produto do seu próprio trabalho, mas, também, aproximam os consumidores da realidade específica da produção e distribuição de alimentos locais/regionais, o que reforça vínculos e sedimenta relações para além de significados 
meramente comerciais. De tal modo, podemos afirmar que, frente a frente, produtores e consumidores tem muito a contribuir um com o outro.

A comercialização direta dos produtos do processo de transição agroecológica recentemente implantado no Assentamento é realizada ainda por meio da participação quinzenal em uma feira agroecológica nas proximidades de um galpão cultural, também no município de Presidente Prudente/SP. Enquanto nas "cestas" os preços dizem respeito a até 15 tipos de alimentos (entre 12 e 15 quilos), o que resulta em valores relativamente maiores (no período em que se deu a realização desta pesquisa - 2016-2019 -, o preço da "cesta" ficou em torno de $R \$ 50,00$ ), na feira agroecológica existe a possibilidade da compra fracionada, na medida exata das necessidades de cada família. Não obstante as pequenas quantidades trazidas para comercialização, derivadas da escala de produção e do limite dos recursos de transporte disponíveis, os produtos colocados à venda geralmente acabam antes do horário programado para o final da feira (Figura 4).

Figura 4: Feira agroecológica dos assentados da Gleba XV de Novembro, realizada no município de Presidente Prudente/SP

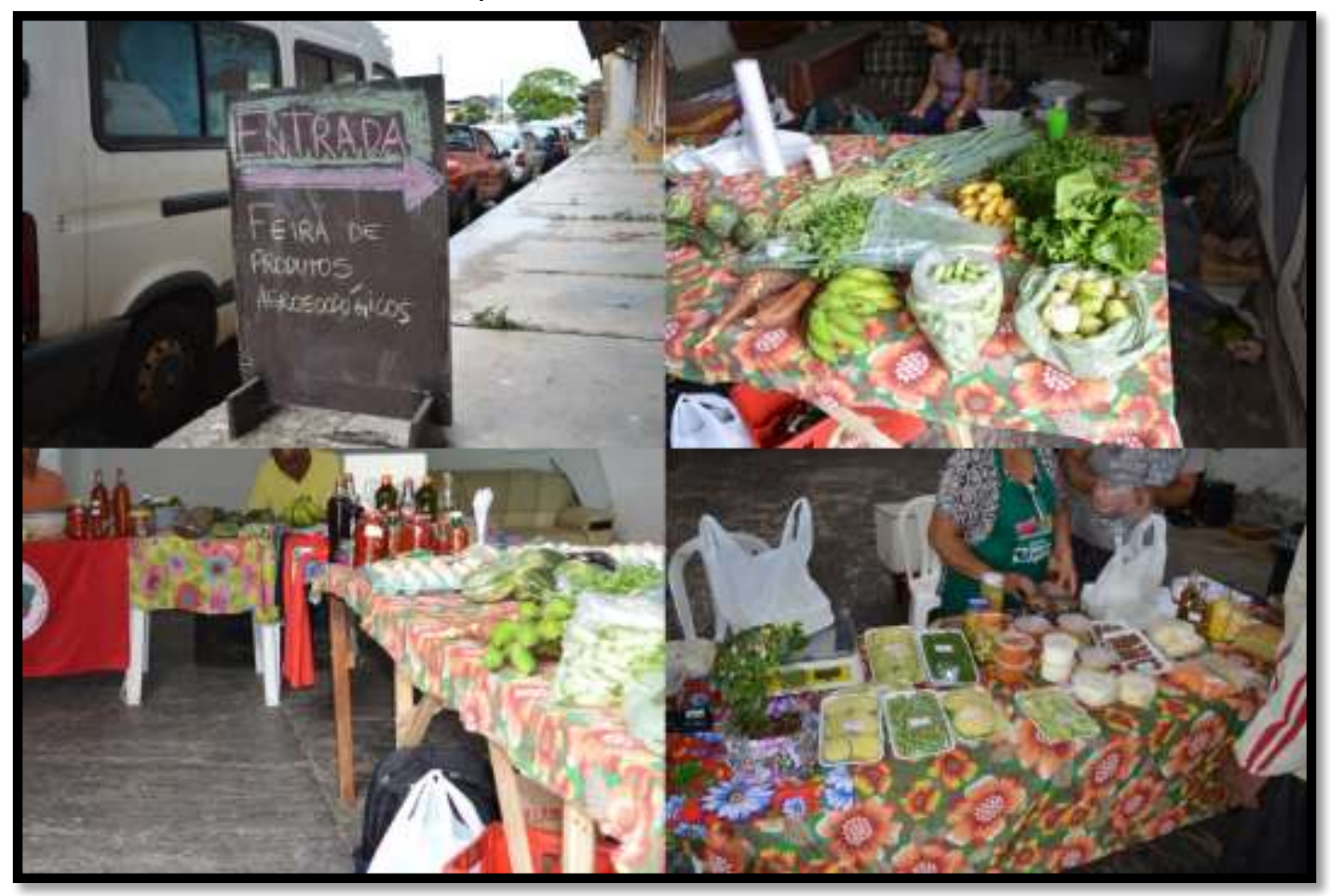

Fonte: trabalho de campo; autor, 2018.

Os consumidores vêm principalmente dos bairros do entorno, porém, com a divulgação realizada em redes sociais e troca de informações entre os frequentadores, cada vez mais pessoas de outros pontos da cidade ficam sabendo e, consequentemente, comparecem para conhecer e comprar os alimentos produzidos com base em princípios agroecológicos. De acordo com consumidores entrevistados, a principal motivação para a 
compra na feira se relaciona com uma postura crítica de preocupação com os efeitos da ingestão continuada de substâncias tóxicas utilizadas na agricultura convencional. É de grande importância, também, o patamar de preços praticados que, em que pese o fato de ser um produto mais caro quando adquirido nos grandes mercados de "nichos" de consumo (Carrefour e Walmart, entre outros), na feira agroecológica não difere daqueles dos alimentos convencionais vendidos nos supermercados, chegando a ser até mais baratos que estes.

Diante da redução dos recursos destinados aos programas oficiais de incentivo à produção e distribuição de alimentos, principalmente o PAA, do qual cerca de metade dos assentados retirava parte expressiva da renda, a participação no projeto das "cestas" agroecológicas (Presidente Prudente/SP e Rosana/SP) e na feira agroecológica de Presidente Prudente/SP permitiu novo fôlego aos assentados. Apesar de ainda não repor a renda proporcionada pela participação nos programas oficiais, estas experiências alternativas permitiram aos assentados continuarem investindo na produção de alimentos, o que deixa abertas as possibilidades de construção de caminhos emancipatórios a partir do controle da produção e da comercialização de alimentos.

\section{CONSIDERAÇÕES FINAIS}

Mais importantes que os resultados imediatos, as experiências de diversificação produtiva, utilização de insumos internos e venda direta ao consumidor, como verificado no caso da Gleba XV de Novembro, mantém vivas as esperanças por um futuro no qual a alimentação traga em si os signos da realização e da soberania e não da dependência e da subalternidade em relação aos atravessadores.

Se hoje a comercialização direta e a transição agroecológica constituem um caminho ainda em construção, esse caminho oferece referências concretas com as quais podem ser trilhadas novas formas de relação entre produtores e consumidores. O encontro é, nesse caso, gerador de estratégias de fortalecimento mútuo que demarcam e consolidam um sistema de produção e abastecimento referenciado no controle local e regional da produção e distribuição de alimentos.

Não obstante, a produção ativa da escala (tanto da produção quanto da comercialização de alimentos) não virá apenas de iniciativas unilaterais efetivadas no âmbito da produção, posto que a transformação do sistema agroalimentar pressupõe também uma tomada de consciência por parte dos consumidores, sem os quais a construção da soberania alimentar efetivamente não se realiza.

Por sua vez, essa "tomada de consciência" não surgirá (somente) como produto de campanhas de informação e convencimento, mas da presença frequente e cada vez mais 
ampla da produção local e regional nas áreas urbanas. Isso porque, ao oferecer alimentos produzidos e comercializados de maneira alternativa e sustentável (variedades crioulas, livres de veneno, de baixa quilometragem e sem a participação de atravessadores), deixa evidências para pensar que outro sistema alimentar é não apenas possível, mas, também, urgente.

\section{REFERÊNCIAS}

ALTIERI, Miguel. Agroecologia. A dinâmica produtiva da agricultura sustentável. Porto Alegre: UFRGS, 2008.

CAPORAL, Francisco Roberto; COSTABEBER, José Antônio. Agroecologia. Enfoque científico e estratégico. Agroecologia e Desenvolvimento Rural Sustentável, Porto Alegre, v. 3, n. 2, p. 13-16, 2002. Disponível em:

<http://www.emater.tche.br/site/multimidia/leitor/11.php\#book/3>. Acesso em: 14 jun. 2020.

GLIESSMAN, Stephen R.; ROSADO-MAY, Francisco; GUADARRAMA-ZUGASTI, Carlos; JEDLICKA, Julie A.; COHN, Avery; MÉNDEZ, V. Ernesto; COHEN, Roseann; TRUJILLOORTEGA, Laura; BACON, Christopher M.; JAFFE, Roberta. Agroecología: promoviendo una transición hacia la sostenibilidad. Ecosistemas, Madrid, v. 16, n. 1, p. 13-23, 2007.

Disponível em:

<https://www.revistaecosistemas.net/index.php/ecosistemas/article/view/134>. Acesso em: 28 jan. 2018.

IBGE. Malha municipal digital (2007). Disponível em:

<ftp://geoftp.ibge.gov.br/malhas_digitais/municipio_2007/>. Acesso em: 03 nov. 2013.

SMITH, Neil. Contornos de uma política espacializada: veículo dos sem teto e a construção da escala geográfica. In: ARANTES, Antônio (org.). O espaço da diferença. Campinas:

Papirus, 2000. p. 132-159.

VIA CAMPESINA. The right to produce and access to land. Rome: Via Campesina, 1996. Disponível em: <http://safsc.org.za/wp-content/uploads/2015/09/1996-Declaration-of-FoodSovereignty.pdf >. Acesso em: 08 nov. 2020.

\section{AGRADECIMENTOS}

Agradecimentos especiais à Fundação de Amparo à Pesquisa do Estado de São Paulo (FAPESP), pelo apoio financeiro que permitiu a construção da tese de doutorado que respaldou a elaboração deste artigo.

Recebido: julho de 2021. Aceito: setembro de 2021. 